\title{
Semeando conhecimentos agrários: o pioneirismo do mestrado em Fitotecnia no Brasil (1961-1981)
}

Sowing agricultural knowledge: the pioneerism of the Masters in crop science in Brazil (1961-1981)

Sembrando conocimientos agrarios: el pionerismo del maestrazgo en Fitotecnia en Brazil (1961-1981)

Tatiani Gomes Gouvêa

Universidade Federal de Viçosa (Brasil)

https://orcid.org/0000-0002-8784-7057

http://lattes.cnpq.br/2378456921920064

tatianigouvea@yahoo.com.br

Edimara Maria Ferreira

Universidade Federal de Viçosa (Brasil)

https://orcid.org/0000-0001-8017-7022

http://lattes.cnpq.br/9811056612626788

edi.ferreir@gmail.com

Denilson Santos de Azevedo

Universidade Federal de Viçosa (Brasil)

https://orcid.org/0000-0001-7938-3427

http://lattes.cnpq.br/6269500390446677

dazevedo@ufv.br

\section{RESUMO}

O artigo analisa as origens e a trajetória do Programa de Pós-Graduação em Fitotecnia da Universidade Federal de Viçosa (UFV), instituição com grande tradição na área das ciências agrárias e considerada como uma das mais importantes do país neste campo de conhecimento. Em 1961, a então Universidade Rural do Estado de Minas Gerais (UREMG), nome anterior da UFV, iniciou o primeiro Curso de Mestrado em Olericultura do país que, em 1964, foi renomeado para Fitotecnia. Tomando por base os conceitos de memória e patrimônio abordados respectivamente, por Le Goff (2003) e Pierre Nora (1993), o levantamento documental e a realização de entrevistas, analisamos o processo de constituição e consolidação deste curso de pós-graduação stricto sensu pioneiro no Brasil, na área das ciências agrárias, entre os anos de 1961 e 1981.

Palavras-chave: História. Pós-Graduação. Ciências Agrárias. 


\begin{abstract}
This article analyzes the origins and trajectory of the Post Graduation Program in crop science of the Federal University of Viçosa (UFV), an institution with a great tradition in the field of agricultural sciences and considered as one of the most important in the country in this field of knowledge. In 1961, the then Rural University of the State of Minas Gerais (UREMG), former name of the UFV, began the first Masters Course in vegetable crops of the country, which in 1964 was renamed to crop science. Le Goff (2003) and Pierre Nora (1993), the documentary survey and the interviews were analyzed based on the concepts of memory and heritage, respectively, and analyzed the process of constitution and consolidation of this course of Post Graduation stricto sensu pioneer in Brazil, in the area of agrarian sciences, between the years of 1961 and 1981.
\end{abstract}

Keywords: History. Post Graduation. Agricultural Sciences.

\title{
RESUMEN
}

El artículo analiza los orígenes y la traeyctoria del Programa de Postgrado em Fitotecnia de la Universidad Federal de Viçosa (UFV), institución con gran tradición en el área de las ciencias agrarias y considerada cómo una de las más importantes del país en este campo de conocimiento. En 1961, la entonces Universidad Rural del Estado de Minas Gerais (UREMG), nombre anterior de la UFV, inició el primer Curso de Maestrazgo en Olericultura del país que, en 1964, fue renombrado para Fitotecnia. Basándose en los conceptos de memoria y patrimonio abordados, respectivamente, por Le Goff (2003 y Pierre Nora (1993), el levantamiento documental y las realización de las entrevistas analizamos el proceso de constitución y la consolidación de este curso de postgrado stricto sensu pionero en Brazil, en el área de las ciencias agrarias, entre los años de 1961 y 1981.

Palabras clave: Historia. Postgrado. Ciencias Agrarias. 


\section{Introdução}

O artigo aborda as origens e a trajetória do Programa de Pós-Graduação em Fitotecnia da Universidade Federal de Viçosa (UFV), instituição federalizada em 1969 e com grande tradição na área das ciências agrárias desde sua fundação, enquanto Escola Superior de Agricultura e Veterinária (ESAV), a partir de 1926 e durante o período da Universidade Rural do Estado de Minas Gerais (UREMG), entre 1948 a 1969.

A ESAV foi concebida pelo Governo do Estado de Minas para ministrar um ensino prático, constituindo-se numa das raras exceções ao predomínio do ensino acadêmico, que ainda vigia na maioria dos estabelecimentos de ensino superior brasileiros da época. A escola foi instituída nos moldes dos Land Grant Colleges americanos - fundamentados na trilogia do ensino, da pesquisa e da extensão direcionados para os problemas da agricultura e dos agricultores e que tanto êxito econômico obtivera no sul e meio oeste dos Estados Unidos da América (EUA), mormente a partir da década de 1880, contribuindo para a difusão de uma agricultura de base científica, com melhores técnicas de produção agrícolas.

A influência deste modelo de estabelecimento na ESAV se intensificou a partir dos anos de 1950, durante a fase da UREMG, na qual se iniciou um processo de modernização da produção agrícola no Brasil, que teve impacto nas décadas seguintes com a chamada Revolução Verde ${ }^{l}$.

Segundo Ribeiro (2005, p. 53), este processo de inovação, que atendia, em parte, aos interesses da oligarquia agrária nacional e ao governo norte-americano, manteve nosso país como agroexportador, subordinado ao mercado internacional sob controle deste país e como aliado político no contexto da Guerra Fria que já estava estabelecida e que se acentuou na América Latina após a revolução cubana (1959), tendo na difusão da pós-graduação stricto sensu, um dos setores estratégicos na propagação de valores vinculados ao sistema capitalista.

É nesse período, conforme Santos (2003), que os Estados Unidos lançaram diversos programas de assistência aos "países amigos", entre eles o Brasil. Estes acordos se desdobraram em uma série de convênios entre escolas e universidades norte-americanas e brasileiras por meio de intercâmbio de estudantes, pesquisadores e professores ${ }^{2}$, em que as fundações norte-americanas tiveram um importante papel no fomento destas ações no campo da ciência, da técnica e da cultura.

Considerando que a UFV desde seus primórdios manteve um vínculo com os Estados Unidos, a política ensejada pela Aliança para o Progresso ${ }^{3}$, fortaleceu estes laços e contribuiu para o aporte de recursos financeiros que permitiram a ampliação de pesquisas agrícolas e a introdução de técnicas de ensino que influenciaram diretamente o modelo adotado por esta instituição de ensino superior.

Neste sentido, os cursos de graduação já não eram mais suficientes para atender às necessidades impostas pelo avanço da ciência e da tecnologia assim como as demandas do mercado de trabalho. Fatores como o crescimento célere da população urbana, o aumento do número de pessoas escolarizadas e a ampliação do número de escolas superiores, fez com que a instalação da pós-graduação passasse a ser premente em algumas universidades brasileiras.

\footnotetext{
${ }^{1}$ A chamada Revolução Verde referia-se a um amplo programa de disseminação de novas sementes e práticas agrícolas, financiado pela Fundação Rockefeller, a partir da década de 1950 nos Estados Unidos e na Europa e, nas décadas seguintes, em outros países.

${ }^{2}$ Conforme SANTOS (2003), as três escolas mais influenciadas pelo modelo norte-americano foram o Instituto Tecnológico de Aeronáutica (ITA), a Universidade Federal de Viçosa (UFV) e a Universidade Federal do Rio de Janeiro (UFRJ).

${ }^{6}$ Esta aliança, firmada em 1961, entre o governo dos Estados Unidos e diversos países da América Latina, consistia num programa de fortalecimento de laços econômicos, políticos e sociais, por meio de acordos de cooperação entre os países envolvidos, no contexto da guerra fria.
} 
É neste contexto que, no início dos anos de 1950, a então UREMG e a Universidade de Purdue, dos EUA, iniciaram uma série de acordos internacionais. Através da Agência para o Desenvolvimento Internacional do Governo Norte-Americano - USAID, a Universidade de Purdue ficou incumbida de escolher uma instituição brasileira que fosse mais compatível para firmar convênio com a instituição norte-americana, estabelecendo intercâmbios com vistas à formação e capacitação de docentes para a educação agrícola e desenvolvimento de pesquisa e atividades de extensão rural. Logo depois de demorada visita à UREMG, o Diretor da Escola de Agricultura de Purdue, na ocasião, Dr. Earl Butz, anunciou que esta instituição fora a escolhida para iniciar o programa (BORGES, 2006, p. 100).

Assim, a UREMG, a partir do ano de 1961 através do estabelecimento de acordos com os EUA, iniciou uma importante fase de desenvolvimento. Foi também nessa época que a instituição passou a receber significativo auxílio financeiro das Fundações Ford e Rockefeller, estreitando ainda mais seu vínculo com os Estados Unidos.

Sobre a Fundação Ford, sabemos que esta iniciou suas atividades no Brasil, no início da década de 1960, tendo como referência física, um escritório localizado no então Distrito Federal, a cidade do Rio de Janeiro.

É que, já em 1960, a Fundação Ford fazia seus contatos iniciais e, logo em seguida, embora não dispusesse de uma sede ou um corpo administrativo permanente, concedia suas primeiras doações a universidades públicas e instituições do governo brasileiro. $\mathrm{O}$ responsável por essas operações iniciais foi Reynold Carlson, que, trabalhando primeiramente em quartos de diversos hotéis e mais tarde, em 1962, na sala de estar do apartamento onde residia no Rio, concedeu as primeiras doações, entre elas uma no total de quase três milhões de dólares (em valores atualizados) a um programa de formação em administração pública, sob a égide de um instituto de pesquisa do governo, a Fundação Getúlio Vargas (FGV), que até hoje figura na lista dos beneficiários da Fundação. (BROOKE e WITOSHYNSKY, 2002, p. 13)

A UREMG foi uma das instituições que mais recebeu incentivos financeiros da Fundação Ford, especialmente na instauração e consolidação de cursos pós-graduados, conforme publicado em diversas reportagens, veiculadas em jornais de circulação local da instituição. Os recursos destinados por esta Fundação, aparentemente, foram importantes para a criação de programas de mestrado e doutorado, contribuindo para que esta Universidade permanecesse como importante centro de excelência, reconhecido internacionalmente, num patamar mais elevado.

Ao que tudo indica, o Instituto de Economia Rural foi o que mais se beneficiou da parceria com a Fundação Ford. Além de ter sido o primeiro departamento da instituição a ter sede própria dentro do campus, recebeu diversos recursos financeiros que possibilitaram a criação do programa de pós-graduação, stricto sensu, em Economia Rural, que, juntamente com o Programa de Pós-Graduação em Fitotecnia (PPG-FIT), ambos iniciados em março de 1961, foram os pioneiros na oferta de cursos pós-graduados em ciências agrárias, no Brasil.

É plausível supor que este fomento permaneceu em vigor ao longo da década de 1960, conforme observa Brooke e Witoshynsky:

Outro exemplo é o total de 6,5 milhões de dólares concedido à Universidade de Viçosa em apenas dois financiamentos, em 1965 e em 1968, numa injeção maciça de recursos num período curto de 
tempo para o desenvolvimento de uma nova instituição de ensino superior voltada para a pesquisa e o ensino da agricultura. (BROOKE e WITOSHYNSKY, 2002, p. 21)

De acordo com estes autores, a Universidade Federal de Viçosa aparecia em $5^{\circ}$ lugar no ranking dos "50 maiores donatários de acordo com o total de doações recebidas (em dólares de 2001)" da Fundação Ford. Nos quatro primeiros lugares, estão a Universidade de São Paulo, Universidade Federal do Rio de Janeiro, a Fundação Getúlio Vargas e a Sociedade Brasileira de Instrução. (BROOKE e WITOSHYNSKY, 2002, p. 50)

Paralelamente à Fundação Ford, outra organização norte-americana atuou junto à UFV, a Fundação Rockefeller. Criada em 1913, esta instituição constituiu-se formalmente como sociedade civil filantrópica, tendo como lema a promoção do bem-estar da humanidade. De modo semelhante à sua congênere, prestou assistência financeira para aquisição de equipamentos, promoveu melhorias na estrutura física e contratou novos docentes para a Universidade de Viçosa.

Ao propiciar condições financeiras e culturais, os acordos firmados possibilitaram a introdução de novas técnicas de ensino e de pesquisa, que potencializaram a modernização da agricultura através da renovação do conhecimento nas universidades rurais, na qual a de Viçosa teve um papel emblemático.

Neste contexto, ainda na década de 1950, o então Departamento de Fitotecnia da UREMG, seguindo uma tradição iniciada pela ESAV em $1937^{4}$ e antevendo a crescente necessidade de maior especialização do seu quadro docente, incentivou e investiu na capacitação de professores que aspiravam realizar treinamento nos Estados Unidos, com o objetivo de aprimorar o saber e o fazer agrário e a utilizar novos métodos e técnicas mais condizentes com a nossa realidade tropical.

Este projeto de treinamento, assinado entre a Universidade de Purdue e a UREMG foi chamado de Projeto 55, devido ao seu número de registro na Agência Norte-Americana para o Desenvolvimento Internacional (USAID) e no Escritório Técnico de Agricultura (ETA), que foi o órgão responsável pela execução dos diversos projetos no Brasil, cada um com um número de registro diferente.

A implantação do projeto 55 do ETA e o intercâmbio entre professores das Universidades de Purdue e de Viçosa, muito contribuiu para o aperfeiçoamento da experimentação e da pesquisa de forma considerável, o que propiciou o surgimento dos primeiros programas de pós-graduação em ciências agrárias do Brasil, sendo que, em março de 1961, o Departamento de Fitotecnia implantou o primeiro programa em nível de mestrado, o de Olericultura ${ }^{5}$ do país, nome este que perdurou até 1964, quando foi renomeado definitivamente para Fitotecnia.

No âmbito nacional, o quadro econômico brasileiro no momento da implantação do mestrado em Fitotecnia, já assinalava uma tendência de mudanças significativas nos modos tradicionais de produção agrícola. A intensificação da agricultura começava a ser realizada por muitos países desenvolvidos e em desenvolvimento, sendo frequentemente denominada de Revolução Verde. À vista disso, a partir da década de 1960, com a modernização da agricultura, destacaram-se alterações nas práticas agronômicas e a incorporação de novas tecnologias que eram até então importadas e que passaram a atender ao aumento da demanda

\footnotetext{
${ }^{4}$ Foi a partir deste ano "que o governo mineiro passou a garantir a liberação, em fluxo contínuo, de dois docentes da ESAV para treinamento de pós-graduação nos Estados Unidos.” (AZEVEDO, 2005, p.106).

${ }^{5}$ É importante destacar que este curso de mestrado ora aparece com o nome de Olericultura, ora com o nome de Hortaliças. Contudo, as primeiras dissertações defendidas expediram o título de Magister Scientiae em Olericultura, atual Fitotecnia.
} 
de produtos agrícolas no mercado externo e de matérias primas no mercado interno, cenário que será consolidado após o golpe militar no Brasil, em 1964.

É nesta conjuntura que nasce o Programa de Pós-Graduação em Fitotecnia da UREMG, no qual analisaremos aspectos relacionados à constituição de seu patrimônio imaterial que começa a ser produzido, a partir de fontes documentais e da memória de alguns sujeitos que tiveram importante participação no processo de criação e consolidação deste curso stricto sensu, pioneiro na área de ciências agrárias do Brasil.

Conforme Candau (2014) as formas de construção da identidade podem ser observadas por meio da memória e estão em permanente construção através da matéria-prima fornecida pelos resquícios deixados por ela, pois é por meio delas que o passado se transforma em um discurso capaz de construir a identidade do grupo perante os outros. E, nesta relação, estão em jogo a lembrança e o esquecimento, que associados a outras fontes documentais, nos auxiliam a organizar/selecionar o conjunto de eventos que, no presente caso, configuram a construção de aspectos relacionados à institucionalização do Programa de Pós-Graduação em Fitotecnia da UFV e a formação do seu patrimônio material e imaterial.

A descrição do percurso, da trajetória de vida do Programa de Pós-Graduação em Fitotecnia, feita a partir da documentação existente, localizada, possibilitou (re)contar esta história, utilizando para isto, o conceito de memória, como categoria de análise da ciência histórica, levando em consideração o caráter polissêmico do termo, em virtude de sua diversidade de sentido, conforme o tipo de informação/documento, sua abrangência e seus usos.

Vale ressaltar que, nas pesquisas bibliográficas realizadas para este levantamento conceitual, encontramos muitas definições para o que se entende por memória. Para os propósitos deste estudo, o significado de memória, bem como a distinção entre memória documental e oral, adotados, nos é apresentada por Bellotto (2005), ao depreender a memória como "um conjunto de informações e/ou documentos, orgânicos ou não" diferenciando o sentido da memória oral em relação à documental ao afirmar que "a memória é referenciadora, e não recolhedora ou armazenadora. Os documentos existem nos seus lugares, sem que se tente reuni-los materialmente. Basta que a informação esteja captada, o objeto identificado, localizado e disponível para o pesquisador". (BELLOTTO, 2005, p. 274)

Assim, somada à memória documental, cabe frisar a importância da história oral, obtida através da prática do recolhimento de lembranças por meio de depoimentos, que agrega uma dimensão viva ao trabalho do pesquisador, uma vez que possibilita uma construção feita no presente a partir de experiências ocorridas no passado e das memórias daí advindas. Através das impressões, vivências e lembranças daqueles indivíduos que se dispuseram a compartilhar sua memória com a coletividade, desfrutamos de um conhecimento do vivido muito mais rico, dinâmico e colorido de situações que, de outra forma, não nos seria possível conhecer.

Nesse sentido, a preservação da memória documental, enquanto elemento primordial para o resgate e manutenção da história institucional, também é uma garantia de acesso às informações, viabilizando a acessibilidade de dados aos cidadãos e tornando-se um importante legado para gerações futuras, que terão a oportunidade de conhecer um pouco melhor o tempo pretérito.

Consoante ao conceito que foi exposto, Le Goff (2003) acrescenta que "a memória, na qual cresce a história, que por sua vez a alimenta, procura salvar o passado para servir ao presente e ao futuro. Devemos trabalhar de forma que a memória coletiva sirva para a libertação e não para a servidão dos homens" (LE GOFF, 2003, p. 471). O autor nos diz ainda que não há história sem documentos, porém cabe a nós, enquanto historiadores, tomarmos a palavra "documento" no sentido mais amplo, considerando os documentos escritos, ilustrados, aqueles transmitidos pelo som, pela imagem ou qualquer outra maneira que possa expressar os acontecimentos já ocorridos. 
Para Nora (1993), o historiador assume cada vez mais um papel central, nesta nova sociedade que opera mudanças de forma cada vez mais veloz. O historiador seria aquele capaz de fazer com que a história não seja apenas história, mas uma narrativa crítica e, neste contexto, surgem os lugares de memória, que para o autor são meios de acesso a uma memória, que já é história por estar reconstituída por meio de vestígios e restos. "Os lugares de memória são, antes de tudo, restos. A forma extrema onde subsiste uma consciência comemorativa numa história que a chama, porque ela a ignora." (NORA 1993, p.12)

Destarte, nossa busca pelas memórias, dados e registros documentais sobre o Programa de Pós-Graduação em Fitotecnia também se coaduna com a narrativa de Gumbrecht (2015) que destaca que o fascínio pelo passado não dá mostras de diminuir. Pelo contrário, o autor atesta que este encantamento parece tratar-se de algo antropológico, algo que aparentemente constitui uma característica matricial das sociedades humanas. À vista disso, argumentamos que o primeiro programa de pós-graduação stricto sensu da UFV e do Brasil, na área de ciências agrárias, tem história e esta precisa ser nutrida, ser alimentada com informações, relatos, registros, fotos e documentos que rememorem seus feitos, as condutas de toda uma geração, dedicada à busca de avanços e melhorias na área da agronomia, na produção de plantas e criação de novas tecnologias visando o aprimoramento da produção agrícola.

Convém ressaltar que, pensar na criação deste curso, nos interesses de seus criadores, no porquê de sua instituição naquele momento específico, poderá resultar hoje, conforme Gumbrecht (2015), em vários passados possíveis, pois o passado é sempre escrito a partir do presente. Por isso que a visão do historiador sobre o passado é, indubitavelmente, de grande importância para a compreensão da realidade atual, haja vista que os modos como enxergamos e nos relacionamos com este pretérito são frutos do momento histórico em que vivemos e que este é constantemente alterado.

Isto posto, reconhecemos que toda instituição deve ter a responsabilidade de cuidar da sua memória e do patrimônio histórico que carrega consigo, por meio da preservação tanto de documentos quanto de objetos, monumentos e relatos que seus atores produzem, propiciando ao público interessado o acesso a informações sobre sua história. Os documentos, além de lembranças, são registros que nos revelam momentos que devem ser conhecidos tornando-se objetos que preservem a memória ou sirvam de pesquisa para esta ser (re)construída.

No caso do patrimônio material verificamos que, conforme as informações disponibilizadas no aplicativo GEOCAPES ${ }^{6}$, no ano de 1998, somente na área de Ciências Agrárias I ${ }^{7}$, contávamos com 757 titulações em nível de mestrado e 277 em nível de doutorado. Dezessete anos mais tarde, ou seja, em 2015, estes números subiram para um total de 2.678 titulados em nível de mestrado e 1.324, em nível de doutorado, o que aponta um crescimento aproximado de $254 \%$ e $378 \%$, respectivamente. Ainda neste mesmo ano, foram titulados 120 estudantes na modalidade de mestrado profissional em Ciências Agrárias I.

Em 2018, o Programa de Pós-Graduação em Fitotecnia é um dos quatro que possui conceito 6 atribuído pela avaliação da CAPES, sendo esta a maior pontuação obtida pelos programas de Fitotecnia da área de Ciências Agrárias I, uma vez que nenhum dos outros recebeu o conceito 7. Os programas classificados, na última avaliação quadrienal da CAPES (2013-2016), com nota 6 foram: Fitotecnia (UFERSA), Fitotecnia (USP), Fitotecnia -

\footnotetext{
6 GEOCAPES - Sistema de Informações Georreferenciadas | CAPES - Disponível em: <http://geocapes.capes.gov.br>. Acesso em: 11 jan. 2018.

${ }^{7}$ De acordo com a CAPES, existem ao todo, 49 áreas de avaliação agregadas por critério de afinidade, em dois níveis: $1^{\circ}$ Nível - Colégios (Colégio de Ciências da Vida, Colégio de Ciências Exatas, Tecnológicas e Multidisciplinar, Colégio de Humanidades) e $2^{\circ}$ Nível - Grandes Áreas. A grande área de Ciências Agrárias I tem como finalidade: estimular a geração do conhecimento e o desenvolvimento científico e tecnológico e promover a transferência dos conhecimentos gerados para aumentar a competitividade e a sustentabilidade do agronegócio do país. Disponível em: <http://www.capes.gov.br/avaliacao/sobre-as-areas-de-avaliacao >. Acesso em:11 jan. 2018.
} 
Produção Vegetal (UFV) e Agronomia - Produção Vegetal (Universidade Estadual Paulista Júlio de Mesquita Filho - UNESP/JAB).

Neste sentido, vale ressaltar que no cenário brasileiro, verificamos a presença de aproximadamente trinta programas de pós-graduação stricto sensu, possuindo denominações diversas como: Agronomia (Fitotecnia), Agronomia (Produção Vegetal), Fitotecnia, Fitotecnia (Produção Vegetal), Produção Vegetal, Produção Vegetal e Bioprocessos Associados e Produção Vegetal no Semiárido, sendo que estes programas possuem como área de concentração, a Fitotecnia ou Produção Vegetal, em que a base de estudos é equivalente, ou seja, o desenvolvimento de técnicas de cultivo e produção de plantas.

Fundamentando a importância representada pela área da Fitotecnia, podemos ressaltar que as pesquisas neste campo de conhecimento disseminaram um conjunto de técnicas para aumentar a produtividade agrícola, por meio do desenvolvimento e aprimoramento dos sistemas de produção das culturas. Também desenvolveu estudos relacionados às práticas de cultivo de lavouras, pomares, hortas, pastagens e de espécies florestais. São atividades que incluem épocas de semeadura ou plantio, épocas de colheita, formas de distribuição das plantas (arranjo e população de plantas), produção de mudas, enxertia, poda de plantas, controle de plantas daninhas, sistemas de rotação, sucessão, consórcio de plantas e de plantio direto, integração entre lavouras, pastagens e espécies florestais. Além disso, já há algum tempo, vem sendo destacada a utilização racional de técnicas, de tal modo que alta produtividade possa ser conseguida sem prejuízo do meio ambiente.

Assim, considerando a atuação de tais programas na formação de cidadãos críticos e com capacidade para participar ativamente nos processos econômicos, sociais e políticos, fazse necessário preservar a memória deste programa, buscando conhecer seu passado, os desafios enfrentados e os êxitos desta trajetória.

\section{As origens do Curso de Pós-Graduação em Fitotecnia na UFV}

Como já mencionado, o Programa de Pós-Graduação em Fitotecnia surgiu no Departamento de Fitotecnia da então UREMG, atual UFV que, por sua vez, se originaram na ESAV, que desde o início de sua construção, em 1921, teve o professor Rolfs atuando na concepção e condução dos trabalhos da escola, permanecendo como seu primeiro diretor até o ano de 1929. Graduado no Land-Grant College de Iowa, EUA, o professor Rolfs, requisitou ainda em 1929, a contratação de mais três professores norte-americanos - Albert Stanley Muller, Albert Oliver Rhoad e Edson Jorge Hambleton, além do professor brasileiro Diogo Alves de Mello, que havia se graduado nos EUA. Esta presença de docentes norte-americanos na ESAV acabou por consolidar uma forma de ensino de caráter eminentemente prático, adotando-se o princípio do "learning by doing" como uma espécie de marca registrada da instituição.

Além de adotar o modelo dos land-grant colleges, a ESAV contou com um grande número de professores estrangeiros e ainda enviou, a partir de 1937, vários docentes brasileiros para realizar treinamento nos Estados Unidos, os quais acabaram disseminando na instituição, ideias e práticas próprias da sociedade norte-americana, ou seja, do americanismo ${ }^{9}$.

Com o intuito de expandir a Escola, no ano de 1948, a ESAV foi transformada em UREMG, passando a ser constituída pelas Escolas Superiores de Agricultura, de Ciências Domésticas e de Veterinária, além da Escola de Especialização (pós-graduação), do Serviço de Experimentação e Pesquisa e do Serviço de Extensão.

\footnotetext{
${ }^{8}$ Processo pelo qual o aprendizado acontece através de atividades experienciais, isto é, por meio do "aprender fazendo".

9 No processo educacional, o "aprender fazendo" tornou-se uma espécie de marca registrada do americanismo. Na ESAV, desde o início, esta teoria foi aplicada e se consolidou ao longo dos anos.
} 
Neste período da universidade estadual rural, um marco importante foi o ano de 1958, quando foi firmado o contrato de colaboração entre a UREMG e a Universidade de Purdue. O projeto intitulado Technical Office of Agriculture ou Escritório Técnico de Agricultura (ETA) - Projeto $55^{10}$ foi estabelecido como resultado de um acordo entre o governo brasileiro e o governo dos Estados Unidos, devendo este último fornecer assistência técnica às Universidades Rurais do Brasil, tendo a UREMG como sede, porque a ideia básica era transformá-la em uma instituição forte, do tipo Land-Grant College.

A implantação do convênio entre a Universidade de Purdue e a UREMG propiciou o surgimento e manutenção de cursos de pós-graduação nesta instituição brasileira, a partir de $1961^{11}$. Tal convênio tinha diversos objetivos, como o de contribuir para reforçar o ensino secundário e superior no Brasil, no setor de agricultura, ciências animais e ciências domésticas, promover o desenvolvimento mais eficiente e proveitoso de programas de pesquisa agrícola em escolas nacionais e outras instituições de pesquisa, prestar assistência na criação de um sistema mais eficaz de divulgação de informações agrícolas às populações rurais e outras, ajudar a desenvolver, no Brasil, a filosofia do tipo Land-Grant College que melhoraria a coordenação entre os três elos (ensino, pesquisa e extensão), ajudar a desenvolver um reconhecimento maior por parte da opinião pública, relativamente à agricultura e ciências domésticas e melhorar a economia do país, por meio de uma agricultura eficiente e de uma vida rural satisfatória.

É importante mencionar que o Conselho dos dois Cursos Pós-Graduados da UREMG ${ }^{12}$, reuniu-se pela primeira vez em 16 de dezembro de 1961, no Gabinete do Serviço de Experimentação e Pesquisa, para tratar basicamente da composição das bancas de defesa de tese dos alunos dos cursos de Economia Rural e Horticultura ${ }^{13}$, levando em consideração o avançado trabalho das teses. As bancas foram compostas e indicadas para os estudantes que estavam em vistas de apresentarem suas defesas, com pequenas variações entre seus membros. Consta ainda na Ata desta reunião inaugural do Conselho ${ }^{14}$, que as bancas definiriam o horário e local das defesas bem como o exame das teses, e os examinadores deveriam concentrar-se no assunto principal podendo ainda estender-se a problemas correlatos.

Vale ressaltar que as primeiras dissertações foram defendidas no mesmo ano de criação do Programa de mestrado em Olericultura, sendo a primeira intitulada "Efeitos da Irrigação e Aplicação de Cálcio sobre a Incidência da Podridão Apical do Fruto do Tomateiro (Lycopersicon esculentum Mill)", defendida no dia 19 de dezembro de 1961, pelo Sr. José de Almeida Soares. O professor Flávio Augusto D’Araújo Couto foi o orientador desta e das outras quatro defendidas no ano de 1961. Este curto prazo para a defesa das primeiras dissertações (menos de dois anos) foi, à época, uma exceção, conforme depoimento dado por este professor orientador:

10 O ETA mantinha diversos projetos no Brasil e cada trabalho possuía uma denominação e numeração diferentes. Em Viçosa, foi denominado ETA - Projeto 55.

${ }^{11}$ Foram iniciados no ano de 1961, os cursos de Mestrado em Olericultura, atual Fitotecnia, e Mestrado em Economia Rural, hoje nomeado de Economia Aplicada.

12 Fonte: UNIVERSIDADE FEDERAL DE VIÇOSA. Ata $\mathrm{n}^{\circ} 1$. Reunião do Conselho dos Cursos PósGraduados da Universidade Rural do Estado de Minas Gerais. Viçosa. Universidade Rural do Estado de Minas Gerais, 16 de dezembro de 1961.

13 Trata-se do Curso de Olericultura, atual Fitotecnia que, conforme já mencionado, por vezes recebeu outras denominações.

${ }^{14}$ Esta reunião inaugural contou com a presença de todos os conselheiros, com exceção do professor José de Alencar. Estiveram presentes os seguintes conselheiros: José Rodolfo Torres (Presidente do Conselho), J. Woods Thomas, Edson Potsch Magalhães, Erly Dias Brandão, Fábio Ribeiro Gomes, Flávio Augusto D’Araújo Couto e Joaquim Mattoso. Como convidado especial também esteve presente o Co-Diretor Americano do Projeto 55, professor Ray M. Lien. 
Como a técnica experimental naquela época já era bem mais desenvolvida e os nossos trabalhos de pesquisa eram todos trabalhos de campo, foram elaborados os projetos de pesquisa juntamente com os alunos pós-graduados e eles fizeram imediatamente as suas dissertações, por isso a nossa foi à primeira ${ }^{15}$.

O Programa de Pós-Graduação em Olericultura, atual Fitotecnia, era, à época de sua criação, pertencente ao Departamento de Horticultura, que juntamente com o de Agronomia deram origem ao Departamento de Fitotecnia, existente até os dias de hoje (BORGES, 2006, p. 226). Já o programa de mestrado em Economia Rural ${ }^{16}$, pertencente ao Departamento de mesmo nome, iniciou suas atividades na mesma época, março de 1961, porém a primeira defesa de tese neste programa, só veio a ocorrer em 19 de junho de $1962^{17}$, pelo discente Filadelfo Brandão.

Em prosseguimento aos investimentos das fundações norte-americanas na UREMG, constatamos que, no ano de 1966, através do apoio da Fundação Rockefeller, foi criado o Banco de Germoplasma de Hortaliças (BGH - UFV), com a finalidade de resgatar espécies nativas ou introduzidas, preservar, documentar e manter intercâmbio de germoplasma entre as diversas regiões do Brasil. Para tanto, os recursos armazenados mediante coleta em diversas partes do país e também recebidos como doação de mais de 100 países, são caracterizados, avaliados e colocados à disposição da comunidade científica nacional.

No final da década de 60, iniciaram-se as primeiras coletas de germoplasma na UFV. As viagens realizadas foram programadas de modo a percorrer cidades ou regiões de colonização antiga e aquelas onde havia notícias da existência de variedades locais desenvolvidas pelos agricultores. As dez primeiras expedições foram realizadas pelos pesquisadores Flávio Augusto D'Araujo Couto e Joênes Pelúzio Campos (professores da UFV) e pelo professor Homer Erickson, da Universidade de Purdue (EUA). (SILVA, 2001, p. 109)

Atualmente o BGH, localizado na Unidade de Ensino, Pesquisa e Extensão (UEPE) denominada Horta Velha, pertencente ao Departamento de Fitotecnia da UFV, possui em seu acervo mais de 8000 subamostras de hortaliças que foram coletadas por estudantes, professores e pesquisadores em diversas partes do Brasil e também recebidas como doação por diversos países.

Face ao exposto e consoante com Gustavo Bianch, "a discussão em torno da força do Projeto Purdue-Viçosa na UREMG/UFV vai além da disponibilidade de recursos e provisão de infraestrutura. $\mathrm{O}$ fortalecimento da noção de igualdade entre ensino, pesquisa e extensão foi enfatizado grandemente dentro do convênio.” (SILVA \& BOTELHO, 2015, p. 54). É evidente que ao apoiar e investir na Universidade, os cientistas americanos esperavam algo em troca, além da publicidade que era dada às doações realizadas à UREMG e que eles nitidamente aprovavam e incentivavam. Havia ainda a submissão de projetos para atender seus interesses e a intencionalidade de possuírem voz ativa no âmbito da instituição mineira.

\footnotetext{
15 Entrevista concedida à TV Viçosa, pelo professor Flávio Augusto D'Araujo Couto, em maio de 2016, no programa "Memória Viva", UFV.

${ }^{16}$ Vale esclarecer que, desde o ano de 2002 este programa é denominado de Economia Aplicada e passou a pertencer a área de avaliação de Economia, de acordo com a classificação da CAPES.

${ }^{17}$ Fonte: UFV - Teses de Pós-Graduação 1961 a 1980. Viçosa: Imprensa Universitária, Universidade Federal de Viçosa, 1982, p. 7.
} 
Não é difícil afirmar que era de interesse da UREMG, e posteriormente da UFV, o fortalecimento desse projeto, sobretudo, no que tange à vinda de recursos para infraestrutura, fomento de pesquisas e, sobretudo, com a oportunidade de complementar a formação nos Estados Unidos. Também, não é difícil notar que a centralidade assumida pela Universidade de Purdue no convênio consistia, dentre outras coisas, impor valores e oferecer caminhos para que a UREMG/UFV se submetesse. Por outro lado, os cientistas embora escolhessem a via de desenvolvimento preconizada pelos EUA desde a origem da Universidade local, a presença americana foi interpretada por alguns brasileiros com alguma resistência. (SILVA \& BOTELHO, 2015, p. 55)

Os reais interesses das Fundações Ford e Rockefeller em investir na área agrária do Brasil, podem dividir opiniões. Sabe-se ainda que, tais agências, disseminaram em nosso meio a cultura e prática científica norte-americana. $\mathrm{E}$ de fato, marcas foram deixadas. $\mathrm{O}$ que não se pode negar é que a partir do estabelecimento destes convênios, a UREMG se expandiu de forma expressiva e vigorosa, fazendo com que se tornasse hoje uma instituição reconhecida nacional e internacionalmente.

Verificamos que desde seu início, em março de 1961, o Programa de Pós-Graduação em Fitotecnia permaneceu pioneiro no país até o ano de 1965, quando foi criado o mestrado do mesmo nome na Universidade Federal do Rio Grande do Sul ${ }^{18}$ (UFRGS), além da criação de outros programas na área de ciências agrárias no Brasil, na década de 1960, como os elencados no quadro a seguir:

Quadro 1: Programas de Mestrado em Ciências Agrárias I no Brasil na década de $1960^{19}$.

\begin{tabular}{|c|c|c|}
\hline Ano de início & Programa & Instituição \\
\hline 1961 & Fitotecnia & UREMG/UFV \\
\hline 1961 & Economia Rural & UREMG/UFV \\
\hline 1962 & Zootecnia & UREMG/UFV \\
\hline 1964 & Estatística e Experimentação Agronômica & ESALQ $^{20}$ \\
\hline 1964 & Fitopatologia & ESALQ \\
\hline 1964 & Genética e Melhoramento de Plantas & ESALQ \\
\hline 1964 & Solos e Nutrição de Plantas & ESALQ \\
\hline 1965 & Ciência do Solo & UFRGS \\
\hline 1965 & Fitotecnia & UFRGS \\
\hline 1965 & Zootecnia & UFRGS \\
\hline 1968 & Entomologia & ESALQ \\
\hline 1968 & Fitotecnia & ESALQ \\
\hline 1968 & Extensão Rural & UFV \\
\hline
\end{tabular}

18 Inicialmente o programa tinha o nome de Pós-Graduação em Agronomia, conforme disponível em: <http://www.capes.gov.br/images/documentos/Documentos_de_area_2017/42_cagr_docarea_2016.pdf> e <http://www.ufrgs.br/agronomia/joomla/index.php/ppgfito-o-programa>. Acesso em: 16 jan. 2018.

${ }^{19}$ Este levantamento refere-se apenas aos programas incluídos na área de avaliação das Ciências Agrárias I da CAPES. Contudo, não podemos afirmar que em outras áreas de avaliação, não tenham surgidos programas de pós-graduação stricto sensu a partir ou mesmo anteriores ao ano de 1961.

${ }^{20}$ Escola Superior de Agricultura "Luiz de Queiroz". 
Reconhecemos que os primeiros programas de pós-graduação stricto sensu desta área tiveram um importante papel no cenário nacional, pois foram de certo modo, os modeladores dos outros programas da área que foram sendo criados. Conforme Federizzi (2007), houve uma significativa influência dos programas mais antigos, de maneira que os programas que se seguiram tiveram e têm uma identidade muito grande com os pioneiros.

O reconhecimento formal dos cursos de pós-graduação no Brasil se deu somente em 1965, por meio do Parecer 977 do Conselho Federal de Educação, segundo o qual o modelo de pós-graduação a ser implantado era adequado à nova concepção de universidade, nos moldes norte-americanos em termos de objetivos e critérios de funcionamento. Apesar do modelo adotado, ter sido, à época, considerado ideal para implantar o sistema de pósgraduação brasileiro, também recebeu críticas de vários autores, devido às diferenças presentes em nosso modelo universitário e o dos Estados Unidos.

Não obstante, tais diferenças de modelo parecem não ter sido relevantes para sua implantação na UREMG, haja vista à sua filiação histórica ao modelo do land grant college, à estrutura departamental, ao regime de créditos semestrais vigentes e ao intercâmbio quase que contínuo da instituição e de seus docentes, desde a época de escola superior isolada, com estabelecimentos congêneres nos EUA, ao longo deste período investigado.

Ao que parece, muito precocemente, o Programa de Pós-Graduação em Fitotecnia veio desempenhando considerável papel no quesito internacionalização e cooperação internacional $^{21}$, recebendo discentes estrangeiros que, no período de 1961 a 1981, representaram 5,5\% do total de estudantes titulados. Entre eles, o boliviano Ramiro Arzabe Antezana $^{22}$, aprovado na defesa de sua dissertação em 16 de abril de 1962, a nona defesa ocorrida no programa. Até o ano de 1981 não houve registro de estudante de nacionalidade estrangeira no curso de doutorado do Programa, cujas primeiras teses foram defendidas no ano de 1977, conforme se verifica na Tabela 1.

Consoante com o mencionado em atas ${ }^{23}$, o Programa recebeu estudantes oriundos de instituições governamentais e privadas, de vários estados brasileiros. Além do salário, tinham custeadas as despesas de acomodação e alimentação, através do projeto de colaboração entre a Universidade de Purdue e a UREMG.

É fato que a pós-graduação concentrou e ainda concentra a maior parte da capacidade de pesquisa nacional, da qual depende a formação de estudantes e professores. A estreita relação entre orientadores e orientandos contribui para o sucesso das pesquisas e deste modo, propiciam (ou não) um ambiente favorável às novas descobertas no campo da produção agrícola.

Neste sentido, na trajetória longeva do Programa de Pós-Graduação em Fitotecnia, muitos foram os docentes que compuseram o rol de orientadores do curso, em seus 55 anos de atividade. Contudo, retrocedendo aos seus anos iniciais, mais precisamente às duas primeiras décadas, entre 1961 a 1981, destacam-se os nomes dos professores Flávio Augusto D’Araújo Couto e Clibas Vieira.

O professor Flávio Augusto D’Araújo Couto iniciou sua carreira no magistério em 1951, como instrutor, no Departamento de Horticultura da então Universidade Rural do Estado de Minas Gerais, UREMG, sendo, dois anos mais tarde, aprovado em concurso público para Professor Assistente em Olericultura. Em 1955, obteve o título de Magister of Science na Universidade da Califórnia-Davis. Foi chefe do Departamento de Horticultura e

\footnotetext{
${ }^{21} \mathrm{Na}$ primeira década de funcionamento, o Programa de mestrado efetuou matrícula de estudantes brasileiros e de outros 7 (sete) países: Bolívia, China, Japão, Panamá, Paraguai, Venezuela e Peru.

22 Orientado pelo professor Flávio Couto, defendeu sua dissertação em 16 de abril de 1962, com o título "Incompatibilidade em Brassica oleracea var.capitata". Fonte: $9^{\circ}$ Relatório Trimestral dos Co-Diretores, 01 de janeiro a 31 de março de 1961.

${ }^{23}$ Atas das $11^{\mathrm{a}}$ e $12^{\mathrm{a}}$ Reuniões Conjuntas do Conselho Consultivo - ETA Projeto 55, 18 de janeiro de 1962.
} 
diretor do Instituto de Fitotecnia e, em 1958, tornou-se Doutor em Olericultura e Jardinocultura. Com a aprovação em concurso de provas e títulos, passou ao cargo de Professor Catedrático, na UREMG.

É pertinente mencionar que o professor Flávio Couto participou decisivamente na formação deste, que foi o primeiro programa da área de Fitotecnia, no Brasil, sendo ainda o orientador da primeira tese de mestrado defendida, em 19 de dezembro de 1961. Foi o professor que apresentou maior número de orientações no decênio 1961-1971, contabilizando 36 orientações, o que demonstra sua importância no processo de formação e consolidação do Programa. Vale destacar que, apesar de ter se aposentado em 1971, ainda concluiu a orientação de seu último pupilo, que defendeu sua tese de mestrado em maio de $1972^{24}$.

Outro personagem de destaque neste processo de construção e consolidação do Programa de Pós-Graduação em Fitotecnia foi o professor Clibas Vieira, conhecido por sua experiência na área de melhoramento do feijoeiro. Formou-se engenheiro agrônomo na UREMG em 1952 e recebeu o título de Magister of Science em Agronomia, em 1958, na Universidade da Califórnia, em Davis, EUA e, na UFV, de Doutor em Agronomia, em 1961, quando defende a tese "Efeitos da adubação verde intercalar sobre o rendimento do milho", e de Professor Catedrático, em 1962, com a tese "Contribuição ao melhoramento do feijoeiro (Phaseolus vulgaris L.), no Estado de Minas Gerais"25.

Atuou como orientador do Programa a partir de 1962 e coorientou estudantes e fez parte de várias bancas de defesa. Considerando apenas o período compreendido entre 1961 a 1981 foram 36 orientações de mestrado. Além disso, o professor Clibas publicou 248 artigos científicos, em revistas com corpo editorial e 255 resumos de pesquisa. Recebeu 27 distinções (VIEIRA, 2009, p. VII). Ademais, ocupou diversos cargos administrativos na UREMG/UFV e participou ativamente em apresentações de trabalhos e/ou seminários, presidindo reuniões, ministrando cursos, sempre divulgando o nome do Programa de Pós-Graduação em Fitotecnia entre seus pares ${ }^{26}$.

No período de 1961 a 1981, os professores Flávio Augusto D’Araújo Couto e Clibas Vieira, contabilizaram um maior número de orientandos, se comparados aos demais orientadores da mesma época. Esta desproporção inicial parece bem razoável, visto que o número de orientadores no começo do curso era bem reduzido e que novos nomes foram lentamente sendo incorporados ao rol de orientadores.

Muitos foram os personagens que fizeram parte desta história, que já ultrapassa meio século de existência e aqui destacamos apenas dois membros emblemáticos desta trajetória, diante da impossibilidade de nomear todos os sujeitos, dando-lhes os devidos créditos neste percurso. Contudo, é notável o esforço de professores, estudantes, secretários e auxiliares, na construção, manutenção e aperfeiçoamento deste Programa de Pós-Graduação em Fitotecnia, visto que, este processo é, antes de tudo, fruto de uma construção contínua, dependendo sempre da parceria e dedicação de seus atores.

Neste sentido, como resultado do patrimônio produzido por este Programa ao longo de pouco mais de meio século de vida, contabiliza-se um expressivo número de defesas (Tabela 1), já ultrapassando 1.600 no total, composto por 1.111 dissertações e 513 teses defendidas até o ano de 2017, sendo que seu corpo docente atual é formado por 36 professores, que orientam a formação de futuros profissionais voltados para a solução de problemas relacionados com a agricultura e preservação do meio ambiente.

${ }^{24}$ Trata-se do estudante Ulysses Soares, que defendeu sua tese de mestrado em 27/05/1972, intitulada: "Estudo da produção e rendimento industrial de oito cultivares de pimentão (Capsicum annuum L.)".

${ }^{25}$ Personagens e Pioneiros da UFV. Disponível em: 〈http://http://www.personagens.ufv.br/>. Acesso em: 15 jan. 2018.

${ }^{26}$ Ocupou diversos cargos administrativos na UFV, como Diretor da Escola de Pós-Graduação (1965-1969), Chefe do Departamento de Fitotecnia (1972), Presidente da Comissão Editorial da Revista Ceres (1972-1973 e 1975-2004) e Pró-Reitor Acadêmico (1984-1988). Seu falecimento ocorreu em 18 de outubro de 2004, aos 77 anos de idade. 
Tabela 1: Total de defesas de mestrado e doutorado no Programa de Pós-Graduação em Fitotecnia da UFV (1961 - 2017).

\begin{tabular}{|c|c|c|c|}
\hline Ano & $\begin{array}{c}\text { Defesas } \\
\text { Mestrado }\end{array}$ & $\begin{array}{c}\text { Defesas } \\
\text { Doutorado }\end{array}$ & Total \\
\hline 1961 & 5 & - & 5 \\
\hline 1962 & 4 & - & 4 \\
\hline 1963 & 2 & - & 2 \\
\hline 1964 & 5 & - & 5 \\
\hline 1965 & 4 & - & 4 \\
\hline 1966 & 5 & - & 5 \\
\hline 1967 & 6 & - & 6 \\
\hline 1968 & 6 & - & 6 \\
\hline 1969 & 12 & - & 12 \\
\hline 1970 & 20 & - & 20 \\
\hline 1971 & 13 & - & 13 \\
\hline 1972 & 23 & - & 23 \\
\hline 1973 & 15 & - & 15 \\
\hline 1974 & 22 & - & 22 \\
\hline 1975 & 25 & - & 25 \\
\hline 1976 & 28 & - & 28 \\
\hline 1977 & 27 & 2 & 29 \\
\hline 1978 & 24 & 2 & 26 \\
\hline 1979 & 26 & 3 & 29 \\
\hline 1980 & 23 & 3 & 26 \\
\hline 1981 & 13 & 2 & 15 \\
\hline 1982 & 18 & 3 & 21 \\
\hline 1983 & 15 & 4 & 19 \\
\hline 1984 & 17 & 1 & 18 \\
\hline 1985 & 18 & 4 & 22 \\
\hline 1986 & 13 & 2 & 15 \\
\hline 1987 & 15 & 4 & 19 \\
\hline 1988 & 23 & 6 & 29 \\
\hline 1989 & 9 & 5 & 14 \\
\hline 1990 & 15 & 7 & 22 \\
\hline 1991 & 21 & 6 & 27 \\
\hline & & & \\
\hline
\end{tabular}

\begin{tabular}{|c|c|c|c|}
\hline Ano & $\begin{array}{c}\text { Defesas } \\
\text { Mestrado }\end{array}$ & $\begin{array}{c}\text { Defesas } \\
\text { Doutorado }\end{array}$ & Total \\
\hline 1992 & 18 & 10 & 28 \\
\hline 1993 & 29 & 7 & 36 \\
\hline 1994 & 21 & 8 & 29 \\
\hline 1995 & 17 & 11 & 28 \\
\hline 1996 & 24 & 10 & 34 \\
\hline 1997 & 31 & 16 & 47 \\
\hline 1998 & 21 & 16 & 37 \\
\hline 1999 & 22 & 12 & 34 \\
\hline 2000 & 22 & 7 & 29 \\
\hline 2001 & 24 & 18 & 42 \\
\hline 2002 & 31 & 16 & 47 \\
\hline 2003 & 26 & 19 & 45 \\
\hline 2004 & 27 & 15 & 42 \\
\hline 2005 & 24 & 17 & 41 \\
\hline 2006 & 22 & 18 & 40 \\
\hline 2007 & 31 & 15 & 46 \\
\hline 2008 & 21 & 20 & 41 \\
\hline 2009 & 23 & 22 & 45 \\
\hline 2010 & 21 & 17 & 38 \\
\hline 2011 & 24 & 25 & 49 \\
\hline 2012 & 24 & 20 & 44 \\
\hline 2013 & 36 & 44 & 80 \\
\hline 2014 & 17 & 31 & 48 \\
\hline 2015 & 29 & 25 & 54 \\
\hline 2016 & 26 & 19 & 45 \\
\hline 2017 & 28 & 21 & 49 \\
\hline & 1.111 & 513 & 1624 \\
\hline
\end{tabular}

Fontes: Sistema Gestor de Pesquisa e Pós-Graduação - $\quad$ SGPPG e Programa de Pós-Graduação em Fitotecnia.

\section{Considerações finais}

Diante do exposto e considerando a relevância do Programa de Pós-Graduação em Fitotecnia da UFV e sua trajetória ao longo dos anos, justifica-se a importância de rememoração deste passado. Conforme a última classificação na avaliação da CAPES, quadriênio 2013-2016, este foi um dos quatro programas que recebeu nota 6 , considerada de "excelência", sendo que, de acordo com a Plataforma Sucupira, em todo o Brasil existem aproximadamente, trinta instituições de ensino que ofertam programas de pós-graduação com denominações similares e base de estudos equivalentes, alocados na área de Ciências Agrárias I da CAPES. 
Cabe destacar ainda que, a presença marcante de cursos relacionados à área agrária mantém-se fortemente percebida na Universidade Federal de Viçosa, sobretudo no âmbito da pós-graduação stricto sensu, pois a natureza agropecuária da instituição só se fortaleceu ao longo dos anos. Não obstante, outras áreas também foram se destacando, o que faz da UFV um espaço plural para aprendizagem, através da adoção de um conjunto de atividades acadêmicas coerente com o conceito da moderna universidade, tendo em vista que a interação das diversas áreas aperfeiçoa os resultados das pesquisas desenvolvidas.

Neste contexto, podemos concluir que a memória é essencial para o estudo da história não só deste Programa como de todo e qualquer legado humano. Além disso, esta memória complementada pela história oral possibilita o desenvolvimento de pesquisas e conhecimentos que contribuam com a sociedade, possibilitando uma maior aproximação da comunidade com seu patrimônio cultural e cientifico.

Nesta perspectiva, a constituição e preservação de um acervo histórico e documental sobre aspectos da história do PPG-FIT são fontes para o desenvolvimento de outros projetos, serviços e consultas variadas, dando apoio às ações institucionais e ao conhecimento de sua história. A memória institucional, concebida com base nos dados de sua própria trajetória ressalta a importância de cada sujeito dentro deste contexto, pois o trabalho desempenhado pelas pessoas ganha novo sentido a partir do momento em que elas conhecem a história na qual se inserem. Desta forma, os indivíduos podem se transformar em agentes de fortalecimento da cultura, colaborando para sua perpetuação ao longo dos tempos, de forma a favorecer a construção de significados e consciência crítica por parte dos mesmos.

Vale ressaltar ainda que, a implantação dos cursos de pós-graduação stricto sensu na UFV, em 1961, ocorreu devido às precondições existentes para sua oferta, uma vez que a instituição já contava com um número considerável de professores doutores e havia demanda por este nível de ensino. Essa iniciativa representou uma antecipação aos dispositivos legais emanados do Conselho Federal de Educação em $1965^{27}$, sendo a UFV precursora no âmbito das ciências agrárias no Brasil e pioneira na pós-graduação brasileira, conforme mencionado na publicação de Massarani (2002).

Chamamos a atenção para o fato de que a preservação do patrimônio institucional e da memória, seja ela documental, arquivística, científica, institucional ou governamental, é uma forma eficaz de proporcionar à sociedade o conhecimento de outra época, buscando no passado, elementos que auxiliem na compreensão e (re)construção do caminho percorrido, possibilitando a noção de continuidade de toda uma geração, bem como, o entendimento do presente com vistas à construção do futuro.

Através deste estudo, concluímos que o Programa de Pós-Graduação em Fitotecnia nasceu, principalmente, em função de uma conjuntura internacional favorável, mas também em virtude do ideal, persistência e dedicação dos professores pioneiros, pertencentes ao Departamento de Fitotecnia da antiga UREMG. Reconhecemos que, apesar de consolidado em sua área, encontra-se em constante processo de construção e reconstrução, com vistas a acompanhar os avanços da ciência, à utilização de novas tecnologias para o ensino e no desenvolvimento de pesquisas mais direcionadas para as necessidades da população, buscando contribuir para que mais profissionais possam ser qualificados a atuarem de forma competente e inovadora, impulsionando o progresso científico e tecnológico do país.

\footnotetext{
27 Definição dos cursos de pós-graduação - Parecer no 977/65, C.E.Su, aprovado em 3-12-1965. Disponível em: <https://www.capes.gov.br/images/stories/download/legislacao/Parecer_CESU_977_1965.pdf〉. Acesso em: 28 maio 2018 .
} 


\section{Referências}

AZEVEDO, Denilson Santos de. Melhoramento do Homem, do Animal e da Semente - O Projeto Político Pedagógico da Escola Superior de Agricultura e Veterinária do Estado de Minas Gerais (1920-1948): Organização e Funcionamento. 2005. 220 f. Tese (Doutorado em Educação) - Universidade de São Paulo, São Paulo, 2005.

BELLOTTO, Heloísa Liberalli. Arquivos permanentes: tratamento documental. $3^{\mathrm{a}}$ Edição. Rio de Janeiro: Fundação Getúlio Vargas, 2005. https://doi.org/10.11606/issn.2316$\underline{901 X . v 0 i 35 p 215-216}$

BORGES, José Marcondes; SABIONI, Gustavo Soares; MAGALHÃES, Gilson Faria Potsch. A Universidade Federal de Viçosa no Século XX. 2a Edição. Viçosa: Editora UFV, 2006.

BRASIL. Conselho Federal de Educação. Parecer n 977/65. Definição dos cursos de pós-graduação. Brasília, 1965. Disponível em: <http://www.capes.gov.br/capes〉. Acesso em: 19 maio 2016.

BROOKE, Nigel; WITOSHYNSKY, Mary (org.). Os 40 anos da Fundação Ford no Brasil: uma parceria para a mudança social. São Paulo: EDUSP, 2002.

CANDAU, Joël. Memória e Identidade. 1ª Edição. São Paulo: Contexto, 2014.

CAPES. Coordenação de Aperfeiçoamento de Pessoal de Nível Superior. Documento de Área. Disponível em: <http://www.capes.gov.br/images/documentos/Documentos_de_area_ 2017/42_cagr_docarea_2016.pdf >. Acesso em: 11 jan. 2018.

CAPES. Coordenação de Aperfeiçoamento de Pessoal de Nível Superior. Plataforma Sucupira: Dados cadastrais do Programa. Disponível em: <https://sucupira.capes.gov.br/sucupira/public/consultas/coleta/programa/listaPrograma.jsf>. Acesso em: 11 jan. 2018.

COUTO, Flávio Augusto D’Araújo. [Maio de 2016]. Viçosa: Programa Memória Viva. Entrevista concedida à TV Viçosa.

FEDERIZZI, Luiz Carlos. A pós-graduação em Fitotecnia no Brasil. Revista Brasileira de Pós-Graduação, v. 4, n. 7, p. 116-140, 2007.

GUMBRECHT, Hans Ulrich. Nosso Amplo Presente: O tempo e a cultura contemporânea.

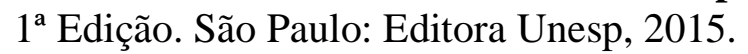

LE GOFF, Jacques. História e Memória. 5a Edição. Campinas (SP): Editora da UNICAMP, 2003.

MASSARANI, Giulio, MASSARANI, Luisa \& COSTA, Teresinha. Alberto Coimbra e a Coppe. $1^{a}$ Edição. Brasília, Paralelo 15 e Coordenação de Aperfeiçoamento de Pessoal de Nível Superior, 2002.

NORA, Pierre. Entre memória e história: a problemática dos lugares. Projeto História. São Paulo, PUC-SP, n. 10, p. 7-28, 1993. 
RIBEIRO, Maria das Graças Marcelo. Educação Superior e Cooperação Internacional: o caso da UREMG (1948-1969). In: VII CONGRESO IBEROAMERICANO DE HISTORIA DE LA EDUCACIÓN LATINOAMERICANA, 2005, Quito. Anais... Quito: Universidad Andina Simon Bolívar, 2005. p. 50-63.

SANTOS, Cássio Miranda dos. Tradições e contradições da Pós-graduação no Brasil. Educação e Sociedade, Campinas, São Paulo, v. 24, n. 83, p. 627-641, 2003. https://doi.org/10.1590/S0101-73302003000200016

SILVA, Derly José Henriques da; MOURA, Maria da Cruz Chaves Lima; CASALI, Vicente Wagner Dias. Recursos genéticos do banco de germoplasma de hortaliças da UFV: histórico e expedições de coleta. Horticultura Brasileira (Impresso), Brasília, v. 19, n. 2, p. 108-114, 2001. https://doi.org/10.1590/S0102-05362001000200002

SILVA, Gustavo Bianch; BOTELHO, Maria Izabel Vieira. Os convênios internacionais entre a Universidade de Purdue e UREMG/UFV: A ciência em rede (1958-1973). Caminhos de Geografia, v. 16, n. 54, p. 49-63, 2015.

UNIVERSIDADE FEDERAL DE VIÇOSA. $9^{\circ}$ Relatório Trimestral dos Co-Diretores - 01 de janeiro a 31 de março de 1961.Viçosa, 1961. Datilografado. 14p. Arquivo Central e Histórico da UFV.

UNIVERSIDADE FEDERAL DE VIÇOSA. Atas das $11^{\mathbf{a}}$ e $\mathbf{1 2}^{\mathbf{a}}$ Reuniões Conjuntas do Conselho Consultivo - ETA Projeto 55, 18 de janeiro de 1962. 15p. Arquivo Central e Histórico da UFV.

UNIVERSIDADE FEDERAL DE VIÇOSA. Personagens e Pioneiros da UFV. Disponível em: <http:// http://www.personagens.ufv.br/>. Acesso em: 15 jan. 2018.

UNIVERSIDADE FEDERAL DE VIÇOSA. Teses de Pós-Graduação 1961 a 1980. Viçosa: Imprensa Universitária, Universidade Federal de Viçosa, 1982.

UNIVERSIDADE FEDERAL DO RIO GRANDE DO SUL. Programa de Pós-Graduação em Fitotecnia. Disponível em: <http://www.ufrgs.br/agronomia/joomla/index.php/ppgfito-oprograma>. Acesso em: 02 maio 2017.

VIEIRA, Rogério Faria; ARAÚJO, Geraldo Antônio de Andrade. Clibas Vieira: amor e dedicação. Revista Ceres, v. 56, p. V-VII, 2009. 